\title{
Poesia do Quebec
}

\section{Introdução}

\author{
Renata Maria Parreira Cordeiro
}

Quando, nos anos 60, Pierre Perrault, começou a escrever suas "crônicas de terra e de mar", Toutes Isles, talvez não soubesse que tentava, assim como Jacques Cartier, descobrir um país. De fato, este último, em 1535, descobrindo o caminho do Canadá e penetrando, com hesitação, "nesse rio que vai tão longe, que nunca ninguém foi até o seu fim", tomou posse das margens do Saint-Laurent, e, em seguida, Ihes deu nomes. Foi o que fez, na seqüência, todo um povo e seus poetas na "terra da Nova França", que se tornou o Quebec. Desse modo, Pierre Perrault refaz o caminho de Jacques Cartier e tenta, por sua vez, vislumbrar um país, não mais unicamente em suas paisagens, mas na própria palavra de seus habitantes. Como se o poema pudesse juntar as duas pontas da história.

Tudo isso para dizer que para tratar de sua poesia, temos de falar um pouco do Quebec. Três vezes maior do que a França, o Quebec tem, atualmente, seis milhões de habitantes, majoritariamente francófonos. A província vive confederada com vinte milhões de anglófonos do Canadá e convive com a cultura de duzentos milhões de norte-americanos. A cultura quebequense se torna, assim, segundo a expressão de Jean Royer, uma cultura de resistência.

A cultura quebequense, distinta da cultura dos canadenses ingleses e dos norte-americanos, não conseguiria sobreviver sem uma produção real de sua língua de expressão, o francês. 
No cerne da língua se encontram os poetas. Submetida à lei inglesa, principalmente na seqüência da derrota das Planícies de Abraão, em 1760, a ex-colônia francesa nunca deixou, porém, de encarnar até hoje a cultura francesa em plena América anglófona. Até o século XVIII, portanto, eram poucos os poetas: apenas alguns "viajantes" franceses de passagem. Mas a elite canandense-francesa sempre manteve a cabeça erguida e conseguiu formar seus próprios escritores que, pouco a pouco, recolheram a memória do povo e a que provinha da França. Em 1830, vem a lume a primeira coletânea de poesia. Em 1848, um intelectual, James Huston, organiza um antologia de trechos diversos que haviam sido publicados em jornais, único meio de expressão de um povo dominado pelos ingleses antes de conquistar, passo a passo, certo controle de seu destino.

Em seguida, quando é fundada a Confederação Canadense, em 1867, a província do Quebec começa uma nova etapa de sua identidade. Um século depois, os chamados canadenses franceses se tornarão quebequenses. Desse modo, sua cultura se distinguirá da cultura do resto do Canadá, que é anglófona.

Essas referências históricas são necessárias para compreender os caminhos do Quebec em poesia. Num primeiro momento calcada na poesia da França até o século XIX, de inspiração católica e patriótica, cujos alguns expoentes como François-Xavier Garneau (1809-1866) e Albert Lozeau (1878-1924) são apresentados nesta antologia, a poesia quebequense se abrirá, pouco a pouco, para as correntes estéticas estrangeiras para se tornar autônoma e completa a partir dos anos 50 .

Até a Segunda Guerra Mundial, os poetas vão levar, cada qual à sua maneira, a poesia quebequense à maturidade. Hector de SaintDenys Garneau (1912-1943) morreu como viveu, sozinho. Em Regards et jeux dans l'espace (1937), ele abandona o verso tradicional para recorrer ao verso livre ao qual imagens simples e novas e um sentido inato do ritmo dão uma grande dimensão. Já Cécile Chabot (nascida em 1917) adota o verso tradicional, porém estranhamente recorre a temas mais triviais como o dia-a-dia, o desemprego, a crise econômica, cujo exemplo clássico que figura em todas as antologias é Visions d'Été. 
Poderíamos citar grandes nomes, como Anne Hébert, prima de Saint-Denys Garneau, Rina Lasnier, cuja obra possui uma dimensão espiritual que lembra um pouco Claudel, Alain Grandbois, Gaston Miron, fundador das Éditions de l'Hexagone, entre tantos outros. Infelizmente, sua voz ainda não ecoa em nossos Cadernos de Literatura em Tradução, esperamos que isso não perdure por muito tempo.

Apresentamos, a seguir, como dissemos, dois grandes expoentes do século XIX que assimilaram os movimentos europeus dos séculos XVIII e XIX, bem como o já citado Visions d'Été, e uma pequena amostra de Saint-Denys Garneau.

Quem sabe no próximo número possamos apresentar alguns autores contemporâneos que afirmam seu destino espiritual em poemas emotivos e imaginativos, desempenhando o seu papel de poeta, a saber: refazer o mundo em cada poema. 


\title{
François-Xavier Garneau (1809-1866)
}

\author{
Les Exilés
}

"Hélas! oui, I'air natal manque à notre poitrine. Ici, la sève este lente pour nos corps.

Où sont nos monts, nos pins, nos caps dont l'aubépine, Comme une frange, aime à couvrir les bords?

"Où sont les verts penchants de nos riches vallées, Où l'oeil se plaît à suivre les cordons

Que forment sur les bords des ondes argentées Les toits nombreux de nos blanches maisons?

"Où sont et nos hivers et leurs grands tempêtes, Géants du nord que je regrette ici;

Et ce frimas épais et ces joyeuses fêtes

Où les plaisirs eloignaient le souci?

"Ici, même saison, même ciel monotone;

Le temps à peine y change quelquefois.

Au milieu d'air chaud un vent poudreux bourdonne.

Ah! rendez-nous nos neiges et nos bois." 


\title{
Os Exilados
}

\author{
Renata Maria Parreira Cordeiro
}

"Dor! ao peito o ar natal, como nos tem faltado! Aqui, lenta nos é ao corpo a seiva.

Montes, pinhos, mas onde, e aqueles nossos cabos,

Cujo espinho qual franja cobre as beiras?

"Onde o verde pendor das nossas ricas matas, Em que o olho se compraz nas filas tantas,

Formadas, margeando as ondas cor de prata, Pelos tetos das nossas casas brancas?

"Onde o nórdico inverno e suas grãs torrentes, Os gigantes que aqui me têm faltado;

E o espesso nevoeiro e as festas sorridentes Onde o prazer nos furta dos cuidados?

"Aqui, mesma estação e o céu invariado; O tempo muda só um pouco, às vezes.

No cálido ar, sussura um vento empoeirado. Ah! dai-nos nossas neves, nossos verdes." 


\section{Albert Lozeau (1878-1924)}

\section{Érable Rouge}

Dans le vent qui les tord les érables se plaignent, Et j'en sais un, là-bas, dont tous les rameaux saignent!

Il est dans la montagne, auprès d'un chêne vieux, Sur le bord d'un chemin sombre et silencieux.

L'écarlate s'épand et le rubis s'écoule

De sa large ramure au bruit frais de l'eau qui coule.

Il n'est qu'une blessure où, magnifiquement, Le rayon qui penètre allume um flamboiement!

Le bel arbre! On dirait que sa cime qui bouge A trempé dans les feux mourants du soleil rouge!

Sur le feuillage d'or au sol brun s'amassant, Par instant, il échappe une feuille de sang.

Eł quand le soir éteint l'éclat de chaque chose, L'ombre qui l'enveloppe en devient toute rose!

La lune bleve et blanche au lointain émergeant, Dans la nuit vaste et pure y verse une eau $d^{\prime}$ argent.

E† c'est une splendeur claire que rien n'égale, Sous le soleil penchant ou la nuit automnale! 


\title{
Bordo Vermelho
}

\author{
Renata Maria Parreira Cordeiro
}

Os bordos, no ar que os torce, emitem um lamento, E há um deles, eu sei, de ramalhos sangrentos!

Fica no monte, junto a esse carvalho idoso,

À margem de um caminho escuro e silencioso.

Espalha-se o escarlate e o rubi rubro escorre

Do grão ramo, ao rumor fresco d'água que corre.

Há só uma ferida em que, magno, importante,

Um clarão, penetrando, algo luz, flamejante!

Bela árvore! Em balanço, o cimo, dir-se-ia,

Que mergulha no sol vermelho em agonia!

Da rama ouro, no chão moreno a se empilhar,

De vez em quando, escapa uma folha a sangrar.

E quando a tarde apaga às coisas o fervor,

A sombra a revesti-lo em rosa se faz cor!

A lua azul e branca, ao longe, em noite vasta

E pura, emerge e verte uma água só de prata.

E que claro esplendor, no mundo sem igual, Sob o sol em pendor ou à noite outonal! 


\section{Cécile Chabot (1907- ) Visions D'Été}

La ville n'était qu'un bouge de l'enfer.

Les usines crachaient des flammèches de suie

E† les hommes brûlés, torturés en leur chair,

Traînaient sous le ciel rouge un visage de pluie.

Et j'eus le désir dou des étés purs et bleus

Où l'âme se retrouve en face du silence.

Et je m'en suis allée en refermant les yeux.

De nouveau les ouvrant sur mon pays d'enfance,

J'y vois naître des jours lumineux de soleil,

Des jours si transparents qu'on leur croirait des veines

Où bouillonnent, ainsi qu'un sang riche et vermeil,

La lumière enflammée et les chaudes haleines

Des tropiques lointains. Parfois ils ont du miel

Le goût âcre et sucré, les teintes d'ambre et d'orge

Et quand je mords en eux en regardant le ciel,

$C^{\prime}$ est tout un champ de fleurs que je goûte en ma gorge. 


\title{
Visões de verão
}

\author{
Renata Maria Parreira Cordeiro
}

Um covil infernal, a cidade, mais nada.

Chispas de negro pó indústrias escarravam

E os homens, com a carne em tortura, escaldada,

Sob o vermelho céu rostos-chuva arrastavam.

Louco desejo: azuis verões e imaculados

Onde se encontram alma e silêncio de frente.

Assim, moça, eu me vou, com os olhos fechados.

E na estação da infância os abro novamente,

Vejo dias de sol, luminosos, nascendo,

Veias, diriam ser, em sua transparência,

Onde, qual sangue rico e escarlate, fervendo

Fulge luz inflamada e brisas em ardência

Dos trópicos ao longe. Às vezes têm do mel

Agridoce sabor e, da cevada, o veio

E quando neles mordo, olhando para o céu,

Um campo só de flor na boca saboreio. 


\section{Saint-Denys Garneau (1912-1943)}

\section{Accompagnement}

Je marche à côté d'une joie

$D^{\prime}$ une joie que n'est pas à moi

D'une joie à moi que je puis pas prendre

Je marche à côté de moi en joie

J'entends mon pas en joie qui marche à côté de moi Mas je ne puis changer de place sur le trottoir Je ne puis pas mettre mes pieds dans ces pas-là et dire voilà c'est moi

Je me contente pour le moment de cette compagnie Mais je machine en secret des échanges

Par toutes sortes d'opérations, des alchimies,

Par des transfusions de sang

Des déménagements d'atomes par des jeux d'équilibre

Afin qu'un jour, transposé,

Je sois porté par la danse de ces pas de joie Avec le bruit décroissant de mon pas à côté de moi Avec la perte de mon pas perdu s'etiolant à ma gauche

Sous les pieds d'un étranger qui prend une rue transversale. 


\title{
Acompanhamento
}

\author{
Renata Maria Parreira Cordeiro
}

Caminho ao lado de uma alegria

De uma alegria que não é minha

De uma alegria minha que eu não posso pegar

Caminho ao meu lado com alegria

Ouço o meu passo com alegria caminhando ao meu lado (...)

Mas não posso pôr os pés nesses passos e

dizer ei sou eu

Contento-me agora com essa companhia

Mas maquino em segredo trocas

Por todos os tipos de operações, alquimias,

Por transfusões de sangue

Mudanças de átomos por jogos

de equilíbrio

A fim de que um dia, transposto,

Eu seja levado pela dança desses passos de alegria

Com o ruído decrescente do meu passo ao meu lado

Com a perda do meu passo perdido estiolando-se à minha esquerda

Sob os pés de um estrangeiro que pega uma rua transversal. 


\section{C'est là sans appui}

Je ne suis pas bien du tout assis sur cettte chaise E† mon pire malaise est un fauteil où l'on reste Immanquablement je m'endors et i'y meurs.

Mais laissez-moi traverser le torrent sur les roches Par bonds quitter cette chose pour celle-là Je trouve l'équilibre impondérable entre les deux $C^{\prime}$ est là sans appui que je me repose.

\section{Sem apoio}

\section{Renata Maria Parreira Cordeiro}

Não estou nada bem sentado nessa cadeira

E meu pior mal-estar é uma poltrona em que se fica Infalivelmente adormeço e nela morro.

Mas deixem-me atravessar a torrente sobre as rochas Por saltos deixar isto por aquilo

Eu encontro o equilíbrio imponderável entre os dois É sem apoio que repouso. 


\section{Les Ormes}

Dans les champs

Calmes parasols

Sveltes, dans une tranquille élégance

Les ormes sont seuls ou par petites familles

Les ormes calmes font de l'ombre

Pour les vaches et les cheveaux

Qui les entourent à midi.

Ils ne parlent pas

Je ne les ai pas entendus chanter

Ils sont simples

Ils font de l'ombre légère

Bonnement

Pour les bêtes.

\section{Os Olmos}

Renata Maria Parreira Cordeiro

Nos campos

Calmos guarda-sóis

Esbeltos, numa tranqüila elegância

Os olmos estão sós ou em pequenas famílias

Os olmos calmos fazem sombra

Para as vacas e os cavalos

Que os cercam ao meio-dia.

Não falam

Não ouvi qualquer canto seu

São singelos

Fazem leve sombra

Bondosamente

Para os bichos. 


\title{
Baigneuse
}

Ah, le matin dans mes yeux sur la mer

Une claire baigneuse a ramassé sur elle toute la lumière du paysage.

\section{Banhista}

\author{
Renata Maria Parreira Cordeiro
}

Ah, manhã nos meus olhos sobre o mar

Uma clara banhista recolhe sobre si

toda a luz da paisagem. 